\title{
Construcción biográfica del saber pedagógico de una maestra migrante venezolana en Boyacá ${ }^{1}$
}

\author{
Biographical construction of the pedagogical knowledge \\ of a Venezuelan migrant teacher in Boyacá \\ A construção biográfica do conhecimento pedagógico de \\ uma professora venezuelana migrante em Boyacá \\ Wüxampüramgen wiñokintun kimeltuwün kimün kiñe \\ ka mapuche kimeltufe Venezuela fey Boyacágepulu
}

\author{
Jaime Andrés Argüello Parra ${ }^{2}$ \\ Universidad Pedagógica y Tecnológica de Colombia \\ Grupo de investigación HISULA - UPTC
}

Recepción: 12/09/2018

Evaluación: 08/05/2019

Aceptación: 23/05/2019

Artículo de Investigación

DOI: https://doi.org/10.19053/01227238.9741

El artículo es resultado de una investigación cuyo objeto es la construcción biográfica del saber pedagógico de la maestra Narvelis Rondón, migrante venezolana en Boyacá, en el contexto de la crisis social y económica de Venezuela de los últimos años. Metodológicamente, se reconstruye la trayectoria de la maestra migrante desde un ejercicio narrativo fundamentado en entrevistas biográficas y en un taller compartido de memoria. Las pautas para conducir la narración biográfica en clave

\section{MEN}

de saber pedagógico atendieron cuatro áreas de indagación: surgimiento de la vocación docente y proceso de formación profesional; modo como se ha desarrollado la carrera docente; la experiencia de la migración; $y$, finalmente, reinvención del quehacer cotidiano.

Dentro de los resultados, el saber pedagógico se estructura en dos grandes bloques de sentido. El primero abarca la relación experiencial con el conocimiento que incluye la formación ética,

1 El artículo es resultado de la investigación "Historias de vida de maestros migrantes en Colombia, Guatemala y España, siglos XXXXI”, perteneciente al Grupo Historia y Prospectiva de la Universidad Latinoamericana - HISULA, código SIG 2391, financiado por la Universidad Pedagógica y Tecnológica de Colombia, UPTC.

2 Doctor en Pedagogía Universidad Nacional Autónoma de México, UNAM-University of Łódź (Polonia). Posdoctorado en Educación, Ciencias Sociales e Interculturalidad. Investigador del Grupo HISULA, docente Escuela de Ciencias Sociales, Facultad de Ciencias de la Educación, Universidad Pedagógica y Tecnológica de Colombia, UPTC. Correo electrónico: jaime.arguello@uptc.edu. co 
la formación práctica del maestro, el sentido crítico en la acción política y la transformación cultural como perspectiva de retorno. El segundo eje comprende el saber migratorio en sí mismo basado en la dialéctica arraigo-desarraigo con impacto en las distintas dimensiones humanas de la maestra con una singular expresión de movilidad social regresiva propia de la migración Sur-Sur.

Como conclusión, la migración permite destacar el papel del educador como constructo social y sujeto cultural. Esta visión contribuye a comprender las transformaciones humanas por la transacción de experiencias e identidades que inciden en un nuevo relato de nación desde la articulación entre pedagogía y perspectiva biográfica.

Palabras clave: saber pedagógico; formación docente; migración; estudios biográficos; Revista Historia de la Educación Latinoamericana.

\section{ABSTRACT}

This article is the result of a research work focused on the biographical construction of the pedagogical knowledge of Narvelis Rondón, a Venezuelan migrant teacher in Boyacá, in the framework of the current socioeconomic crisis in Venezuela. The methodology consisted in a narrative exercise that aimed to reconstruct the trajectory of the migrant teacher through biographical interviews and a workshop to share memories. The guidelines for conducting the biographical narrative focused on four main areas: emergence of the teaching vocation and professional training process; development of the teaching career; the experience of migration; and reinvention of everyday life. Within the results, the pedagogical knowledge is structured in two big blocks of meaning. The first covers the experiential relationship with knowledge, including ethical training; practical teacher training, critical sense in political action, and cultural transformation as a perspective of return. The second one comprises the migratory knowledge itself based on the rooting and uprooting dialectic with impact on the different human dimensions of a teacher with a unique expression of regressive social mobility; characteristic of South-South migration. In conclusion, migration highlights the role of the teacher as a social construct and as a cultural subject. This vision contributes to understanding human transformations through the transaction of experiences and identities that influence a new nation story from the articulation of pedagogy and a biographical perspective.

Keywords: pedagogical knowledge; teacher training; migration; biographical studies; Journal History of Latin American Education

\section{RESUMO}

$\mathrm{O}$ artigo apresenta o desenvolvimento de uma investigação, cujo objetivo é a construção biográfica do conhecimento pedagógico da professora Narvelis Rondon, uma imigrante venezuelana em Boyacá, no contexto da crise económica e social na Venezuela nos últimos anos. Metodologicamente, o estudo reconstrói a trajetória da professora migrante a partir do exercício de narrativa baseado em entrevistas biográficas e em uma oficina de memória partilhada. As orientações para a produção da narrativa biográfica em termos de conhecimentos pedagógicos incluíram quatro áreas de investigação: surgimento da vocação docente e processo de formação profissional; modo como desenvolveu-se a carreira docente; a experiência de migração; e, finalmente, uma reinvenção da existência quotidiana.

Como resultado, o conhecimento pedagógico é dividido em dois grandes blocos de sentido. O primeiro abrange a relação vivencial com o conhecimento 
que inclui a formação ética, formação prática do professor, o senso crítico na ação política e a transformação cultural como perspectiva de retorno. $\mathrm{O}$ segundo eixo inclui a conhecimento experiencial da imigração baseado na dialética enraizamento-desarraigamento com impacto nas dimensões humanas da professora com uma expressão singular na mobilidade social regressiva típica da migração Sul-Sul.
Em conclusão, a migração visa ao papel do professor como sujeito cultural e como construção social. Essa visão ajuda a compreender as transformações humanas na transação de experiências e identidades que têm um impacto sobre uma nova história da nação a partir da relação entre a pedagogia e a perspectiva biográfica.

Palavras-chave: saber pedagógico; formação docente; migração; pesquisa biográfica; Revista História da Educação Latino-americana.

\section{PIKÜNOGETUN}

Tüfa chi chijka ta kiñe wenuntun zugu xipalu kiñe inatuzugun mew chew ta pegelgey kimeltuchefe venezuelache mülepulu Boyacá, Narvelis Rondon ñi chumgechi wenuntuniarupuy ñi pedagógico kimün, ragiñ weza zugu ka fija zugu mülelu Venezuela fantepu mew.

Zewmayael tüfa chi chijka, wüñoazkintugey kimeltuchefe ñi küzaw ramtukan güxam mew ka kiñe taller chew ta tukulpagey kuyfike zugu. Feypial ñi pedagógico kimün azkünugey meli zugu ñi inatuzugugeal: chem zugu mew ayüy ñi kimeltuchefegeal ka chumgechi kimeltugey ñi kimeltuchefegeal; chumgechi amulerupuy ñi kimeltuchefegen; chumgechi xipay ñi mapu mew; inagechi chumgechi inanierupukey fijantü ñi küzaw. Wenuntun zugu mew pedagógico kimün niey epu füxake zugu. Wünelu mew müley ta chumgechi nüwküleay kimün egu küzaw, fey mew koneltuley kimeltun nor- chegeal, kimeltun chumgechi küzawael ta kimeltuchefe, ñi günezuamal ñi femün ka waychüftual ta zugu wüño küme mogetuael. Kagelu zugu ta xipamapun kimün mülenmu ta rakizuam tuwkülen kiñe mapu mew ka tuwkülenon kiñe mapu mew ñi chumgechiley ñi mogen ta feychi kimeltuchefe, xipamapun am ta che wiji-wiji mapu püle zoy naqkeürkey warun mew.

Wenuntun zugu mew, xipamapun mew ta kimgey kimgeltuchefe ñi xipan kiñe xokiñche mew ka ñi chew chegen.

Femgechi inazuamgen mew ta zugu, kejuy ñi femgechi günezuamgeal chumgechi amulerupukey ta che ñi mogen ka ñi chumgen egün, fey mew am ta koneltulelu kiñe nación we feypin nüwkülelu ta pedagogía egu inazuamgen ta mogen.

Zichul zugun: pedagógico kimün;, kimeltun kimeltuchefegeal; chijkan mogen; Revista Historia de la Educación Latinoamericana.

\section{INTRODUCCIÓN}

Las aceleradas transformaciones del mundo global han llevado consigo una afectación de los modos de vida, de la constitución de subjetividades y de la manera de asumir el desenvolvimiento de la humanidad. En el complejo mundo de la educación, estas dinámicas han planteado una continua resignificación del ejercicio de la profesión docente donde las condiciones multidimensionales que rodean el desempeño del magisterio, en cualquiera de sus niveles, desde la educación preescolar hasta la educación superior, se han cargado de nuevos y retadores desafíos en el plano epistémico, socio-cultural, político y personal. Es 
así como se hace particularmente explícito el sentido del maestro como sujeto social de relaciones sistémicas e históricas, más aún, como constructor de un saber propio - el saber docente - que actúa como la estructura orientadora de las prácticas docentes y de las acciones humanas. De esta manera, los entramados donde se inscribe el desempeño docente conducen la forma de reconstruir el saber pedagógico, la comprensión de los actores sociales de la educación como sujetos políticos y las trayectorias profesorales como dispositivos de autodeterminación e identidad.

En consecuencia, el punto de partida de este artículo resultado de investigación, es que las maneras de comprender y desarrollar la profesión docente se configuran, además de los dispositivos institucionales normalizados, por la experiencia cotidiana de los sujetos, dentro de la cual se deben considerar las dinámicas de movilidad trasnacional entre Venezuela y Colombia como uno de los fenómenos sociales dominantes de la historia nacional del último lustro.

Las relaciones entre migración y pedagogía, particularmente, las maneras como se rediseñan los mundos de vida del profesorado, parten de la constatación de un hecho sin precedentes en Colombia: flujos migratorios masivos procedentes de Venezuela se han establecido en el territorio nacional.

Las relaciones binacionales entre Colombia y Venezuela cuentan con una vasta historia y tradición. En el plano geopolítico se registran las experiencias emprendidas por la Agenda binacional en la Zona de Integración Fronteriza (ZIF) colombo-venezolana, las cuales han estado determinadas a lo largo del tiempo, con mayor o menor intensidad, según las connotaciones ideológicas de los respectivos partidos de gobierno que han suscrito acuerdos comerciales para la productividad, la sostenibilidad de los mercados, los pactos de seguridad y los programas de intercambio cultural ${ }^{3}$. Durante décadas Venezuela fue un país receptor de miles de colombianos que salieron de sus territorios forzados por el conflicto armado interno o por la radicalización de la pobreza. En la patria de Bolívar, muchos reconstruyeron sus proyectos de vida, crearon empresa, generaron renta y capital en beneficio de sus sistemas familiares. Venezuela apoyó a los colombianos en tiempos de la bonanza petrolera y favoreció su integración al país como fue proclamado en el Decreto 31 de 1977 o Quinto Plan de la Nación.

Según cifras de Migración Colombia, entidad adscrita al Ministerio de Relaciones Exteriores, durante los últimos cinco años es perceptible un crecimiento del movimiento migratorio lo cual es indicativo de una progresiva situación de crisis social y política en la nación vecina. En los reportes de la entidad se indica

3 En el ámbito de las cooperaciones binacionales se puede encontrar la iniciativa académica de la Comisión de Bioética transfronteriza, establecida inicialmente desde la Universidad de Los Andes-Mérida como una propuesta para la fundamentación epistemológica de una concepción bioética amplia a la ciencia, la tecnología, las humanidades y las artes. El proyecto manifiesta un ensamblaje de las intenciones de cooperación de las naciones, de acuerdo con sus contextos histórico-sociales, en el desarrollo de la actividad académica, científica y cultural: "La Comisión que hoy proponemos debe ser llevada al nivel de la Bioética transfronteriza, para darle un contexto en el marco de la crisis que vive la educación, la ciencia, el método científico, la fuga de talentos, la competencia neoliberal de los paradigmas dominantes en Colombia, el agotamiento del paradigma socialista bolivariano en Venezuela, y el estudio de un paradigma emergente del ser humano transfronterizo que pueda dar cuenta de ese espacio geohistórico sometido a una constante crisis por las políticas públicas de los Estados nacionales de lado y lado". José Pascual Mora, "La comisión de Bioética de la Universidad de Los Andes y la fundamentación epistemológica de la comisión de bioética transfronteriza”, Revista Mundo FESC, 10 (2014): 35 . 
que, al término del primer semestre de 2018, 870093 venezolanos ingresaron al país, de los cuales 381735 se hallan regularizados dentro del tiempo de ley establecido o como portadores de visa, cédula de extranjería o Permiso Especial de Permanencia, mientras 442462 censados en el Registro Administrativo de Migrantes Venezolanos en Colombia (RAMV) se encuentran en proceso de regularización. Según este reporte, 45896 se encuentran en estado irregular pues ingresaron sin autorización al país o superaron el tiempo de permanencia ${ }^{4}$. La cifra total con corte a 31 de marzo de 2019 registra más de 1260000 venezolanos en el territorio nacional.

En torno a las cifras deben tenerse en cuenta, por lo menos, dos factores de especial importancia que inciden en su alcance de validez. Por un lado, la volatilidad de los datos, debido a la modificación permanente de los registros por cuenta de la imparable actividad migratoria. Por otro lado, si bien las estadísticas oficiales son útiles para aportar una visión de conjunto sobre el fenómeno a estudiar, resultan insuficientes e incompletas por la dificultad de registrar el ciento por ciento de las características poblacionales. Por ello, diversos medios de comunicación y asociaciones civiles sugieren que estas cifras podrían estar desbordadas por un éxodo masivo de venezolanos no registrados, asunto que anticipa un estado de alerta humanitaria integral dadas las dificultades de atención del país receptor, por su propia condición de emergencia e inviabilidad que dificulta el aseguramiento de los derechos fundamentales aun para los propios nacionales. Más allá de los datos, es el problema de integrar la población migratoria real, no solo a la cotidianidad social sino a la vida productiva y democrática de un país resistente a las formas culturales de otredad.

En ese horizonte de múltiples sectores humanos en movilidad geográfica y cultural, el interés de la presente investigación fue conocer la situación humana de Narvelis Elizabeth Rondón Araujo, una docente migrante establecida en Colombia en búsqueda de alternativas de trabajo, sostenibilidad económica, satisfacción de necesidades esenciales y, en general, mejores condiciones de vida, y cómo dicha experiencia, mediante procesos de biografización, constituye un modo particular de comprender la profesión educadora. Implica, por tanto, la reconstrucción de trayectorias profesionales, articuladas a la historia de vida, para determinar los momentos genealógicos de la docente, su desenvolvimiento profesional en el país de origen, las condiciones de la movilidad transfronteriza, el establecimiento en el nuevo país y el desempeño laboral en el campo educativo - si éste fuera posible - o en otro ámbito de productividad para la generación de ingresos.

Se asume, pues, la configuración de la profesión docente más allá de las regulaciones legales e institucionales sobre la misma, privilegiando, especialmente, la experiencia cotidiana-biográfica de los sujetos.

4 “Migración Colombia, Dinámica migratoria Colombia-Venezuela primer semestre 2018”, Migración Ministerio de Relaciones Exteriores, 2018, acceso el día 3 de agosto de 2018, http://www.migracioncolombia.gov.co/index.php/es/prensa/infografias/7923-infografia-general. 
De esta manera la delimitación del objeto conceptual y empírico de la investigación se recoge en la siguiente pregunta:

¿Cuáles son los sentidos del saber docente en la historia de vida de una maestra venezolana establecida en el departamento de Boyacá, Colombia, durante el periodo 2014-2018?

\section{Fundamentos teóricos}

\section{La migración como hecho multidimensional}

Desde las teorías tradicionales de sistemas migratorios, las relaciones e intercambios no están necesariamente ligados a la cercanía geográfica sino a las expectativas políticas y económicas de distintos sectores poblacionales que procuran el aseguramiento de su destino. Aunque un criterio clave en la naturaleza de estas movilidades es la distinción colonial de naciones centro-periferia por cuanto "los sistemas multipolares son posibles toda vez que un grupo de países centrales dispersos reciben migrantes de un grupo de naciones sobrepuestas de envío" libre conceptual del significado de la migración en el tercer milenio centrado en renovados factores de alerta humanitaria mundial.

Para ayudar a comprender teóricamente el fenómeno social de la migración recuperamos aquí, de manera muy breve, las características más distintivas desarrolladas al respecto y la emergencia de la perspectiva ética global.

Desde la década de los noventa, diversos autores han señalado que una comprensión integral de los procesos de migración contemporánea no se puede alcanzar desde una disciplina exclusiva o desde un solo nivel de análisis. Por el contrario, su carácter multifacético y complejo requiere una teorización sofisticada que incorpore una variedad de perspectivas, niveles y consideraciones ${ }^{6}$. Esta diversidad de teorías y los divergentes niveles de análisis de campo que abordan, se corresponde con el crecimiento progresivo del fenómeno desde el periodo de entreguerras, durante toda la segunda mitad del siglo XX y, de manera renovada, en el tercer milenio.

Las tendencias históricas a lo largo de los últimos cuarenta años en la migración transnacional están referidas a cambios demográficos y no solo a los constreñimientos de tipo económico en los países de origen. En el presente y hacia las décadas venideras, la migración está afectada por las volátiles tendencias y predicciones de la economía global en una combinación socio-demográfica sostenida en el tiempo. Aparecen también nuevos índices de causalidad como desequilibrios poblacionales, inequidad económica extrema, auge de los impactos de la globalización, inestabilidad política debido a las dictaduras orgánicas,

$5 \quad$ Douglas Massey et al., "Theories of International Migration: A Review and Appraisal”, Population and Development Review 19, no. 3 (1993): 454.

6 Ibíd., 432. 
conflictos interétnicos, políticos y religiosos, y la sobrevivencia humana ante la seguridad alimentaria, el cambio climático y la degradación medioambiental. Por todo ello, es notoria la tasa de crecimiento, particularmente desde el 2010 en el ámbito de los cambios socio-demográficos de la globalización, haciendo de este fenómeno uno de los desafíos sociales y políticos más sobresalientes para los países industrializados en el siglo $\mathrm{XXI}^{7}$.

No obstante esta evidente complejización del fenómeno migratorio, aún prevalece la perspectiva que destaca la movilidad por razones laborales integrada a un proceso de desarrollo económico. Así, desde las corrientes inspiradas en el modelo económico neo-clásico, la teoría del capital humano concibe la migración como un movimiento de decisión individual para la maximización de ingresos (micro-nivel de los procesos de decisión). Ese enfoque responde a los requerimientos estructurales de las economías modernas industriales que en último término será una consecuencia más de la globalización económica y su lógica de mercados transfronterizos ${ }^{8}$. Por eso, para el modelo económico neoclásico, los actores individuales deciden migrar debido a un cálculo intencionado de costo-beneficio que les permite esperar un retorno neto positivo, usualmente monetario. La migración internacional se entiende como una forma de inversión en capital humano'.

Desde esta concepción, aun los vínculos culturales que se crean aparecen muchas veces motivados por modelos basados en estilos modernos de consumo, estándares de vida e idiomas extranjeros ligados a referentes hegemónicos de nación en el mundo. Cambio de valores y percepciones culturales orientadas a renovadas formas de consumo, crean un estilo de vida derivado de la cultura de la migración ${ }^{10}$. En consecuencia, a partir de una nueva "distribución regional del capital humano" asociada a los principios de la causalidad acumulativa que se ha venido comentando, el fenómeno migratorio contribuye a la acentuación de brechas sociales debido a que "la acumulación de capital humano fortalece el crecimiento económico de los países en las áreas de recepción, mientras mantiene la disminución en las áreas de envío, alentando condiciones para nuevas migraciones" ${ }^{\prime 11}$. Es el círculo que asocia la economía del desarrollo con la migración.

En términos generales, según el análisis de los autores, la migración internacional sigue la organización política y económica de los mercados, sea en términos individuales (salarios diferenciales), de unidades de producción o consumo culturalmente definidas (riesgos relativos) en beneficio de ciertos grupos de referencia, satisfacción de demandas de empleadores con trabajadores de bajo ingreso (esfuerzos de reclutamiento), o la penetración del mercado en regiones periféricas que lleva al desplazamiento internacional de obreros por cuenta de

7 Thu Hien Dao et al., "Global Migration in the 20th and 21st Centuries: the Unstoppable Force of Demography”, FERDI Working Papers, HAL archives-ouvertes, WP223 (1-36) (2018), acceso el día 10 de julio de 2018, https://hal.archives-ouvertes.fr/hal-01743799/ document.

8 Massey, “Theories of International Migration”, 432.

$9 \quad$ Ibíd., 434.

10 Ibíd., 447-452.

11 Ibíd., 453. 
los mercados globales. No obstante, las condiciones económicas originantes se combinan con razones de distinta índole asociadas, por ejemplo, a la expansión de redes de migrantes, o el significado social del trabajo, cuyas concepciones cambian en las sociedades receptoras ${ }^{12}$.

Todo ello representa para los Estados el desafío de mejorar la gestión de los flujos de migración y la coherencia entre desarrollo y políticas migrantes, con el fin de promover una perspectiva amplia de seguridad humana que contemple los derechos fundamentales, la democracia, la paz y la estabilidad social.

Por ello, más allá de las determinantes económicas clásicas que sustentan la migración global, y que tienen una relevancia capital, se destaca aquí desde el enfoque multicausal, las apreciaciones de Lozano y Gandini:

La migración no puede ser concebida entonces como un fenómeno motivado sólo por algún factor (pobreza, insuficiencia o desigualdad de ingresos, bajo nivel de desarrollo económico), sino que parece más apropiado que se comprenda como un proceso social sostenido por varios pilares, con asiento tanto en el origen como en el destino, así como en la propia dinámica de interrelaciones que se construyen entre ambos a través de diversas esferas: económica, social, cultural, idiosincrática, política ${ }^{13}$.

En el caso de la Agenda binacional colombo-venezolana, durante el último lustro se ha ido afianzando este sentido de intervención en múltiples dimensiones a partir de la efervescencia migratoria y la crisis fronteriza. Desde el lado colombiano, la Oficina de Migración del Estado ha ido diseñando programas de reconocimiento del estatus legal en tanto punto de partida para el aseguramiento de derechos fundamentales como la educación, la salud, el empleo y el acceso a la justicia. No obstante, ha sido necesario transitar de la inexperiencia estatal a la creación de programas de gobierno que aún se consideran insuficientes y que han reclamado el concurso solidario de otras naciones latinoamericanas.

\section{Profesión y saber docente}

Dentro del análisis sectorial de las migraciones, el presente estudio se centra en la movilización trasnacional de docentes que implica atender una profunda dimensión de subjetividad, sociedad y ética. Por eso se toman en cuenta los elementos motivacionales del individuo para emprender un periplo migratorio hasta las relaciones emergentes en los contextos político y económico en un marco de actuación biográfico y cultural.

La migración es constitutivamente una experiencia humana sistémica e integral. Por ende, al referirse a ella no se trata sólo de un fenómeno de interés social con alto impacto político, cultural y económico, como se ha descrito en el

\footnotetext{
12 Ibíd., 448.

13 Fernando Lozano y Lucía Gandini, “Migración calificada y desarrollo humano en América Latina y el Caribe”, Revista Mexicana de Sociología 73, no. 4 (2011): 681.
} 
apartado anterior, sino de un sustrato constituyente de subjetividad, esto es, de reinvención axiológica e identitaria ante los propios mundos de vida del maestro como ser personal y como profesional.

Más allá de las consideraciones de la profesión docente que destacan los dispositivos legales e institucionales que le resultan inherentes, en el presente enfoque se resaltan las conexiones que se establecen con el saber pedagógico en el sentido expuesto, entre otros, por Araceli de Tezanos: “Los docentes dicen la palabra de la profesión desde el saber pedagógico que construyen en la reflexión sistemática sobre su práctica cotidiana del enseñar, en consecuencia, es este saber el que marca el camino de la profesionalización docente" ${ }^{14}$.

Singular significación adquiere aquí el vínculo entre saber pedagógico, profesión docente, cotidianidad y acontecimiento vivido como desenvolvimiento de la experiencia humana, puesto que "el enseñar, entendido como oficio, tiene más una condición casuística que causal en tanto se trabaja caso a caso, día a día, en la inmediatez de lo cotidiano"15.

Por eso, la reflexión crítica del oficio de enseñar a partir de la experiencia no debe entenderse sólo desde el conjunto de situaciones instrumentales, legales o estrictamente pragmáticas que rodean la docencia en sí misma, como sistema de funcionalidades en un marco normativo dado. La práctica cotidiana del enseñar no es sólo acatamiento a cierto ámbito restrictivo del oficio sino una expresión privilegiada del ser vital, es decir, antecede un constructo ontológico a la puesta en escena del acto magisterial.

Es necesario aclarar que la construcción de la categoría "saber pedagógico" ha tenido, desde el caso colombiano, una tradición intelectual bien consolidada y diversificada que, en sí misma, daría para un estado del conocimiento que refleje sus vertientes, exponentes y especificidades. Sin embargo, por no pretenderse aquí una Historia de las ideas, no se trata de dar cuenta de todas esas posibles tradiciones en torno al saber pedagógico, sino sólo señalar algunas congruencias para la pretensión de este estudio.

Así, por ejemplo, dentro del enfoque histórico, desde la perspectiva arqueológica y genealógica de Olga Lucía Zuluaga, se resalta la diversidad de registros en los que se inscribe el saber pedagógico en las múltiples relaciones entre sujetos, discursos, prácticas e instituciones ${ }^{16}$. En esa línea, como recuerdan Herrera y Martínez, "La práctica siempre es algo más que aquello que se evidencia en su intencionalidad explícita; en la práctica se hace presente ese cúmulo de discursos, concepciones y procesos de institucionalización"17. En este punto, un ámbito de especial relevancia para nuestro interés, son "las posiciones de sujetos de saber que puede asumir un maestro en determinada formación social"18.

14 Araceli de Tezanos, “Oficio de enseñar-saber pedagógico, la relación fundante", Educación y ciudad. Revista del Instituto para la Investigación Educativa y el Desarrollo Pedagógico, n.o 12 (2007): 14.

15 Ibíd., 11.

16 Olga Lucía Zuluaga, Pedagogía e historia (Bogotá: Siglo del Hombre-Universidad de Antioquia, 1999).

17 José Darío Herrera y Ángela Martínez, “El saber pedagógico como saber práctico", Pedagogía y Saberes, n.o 49 (2018): 15.

18 Ibíd., 14. 
La acción como entramado del saber debe entenderse más allá del plano estrictamente profesional de los docentes. El saber pedagógico no sólo aparece referido a la enseñanza como oficio sino a un sistema humano multidimensional recapitalizado por la reflexividad y la crítica. En ese sentido, como apunta Zambrano, "el saber pedagógico no determina al sujeto, más bien este se narra en el sentido de su acción pedagógica. Se llega a ser pedagogo por la reflexión sobre la acción" 19 .

El enclave de la acción pensada es la arquitectónica existencial. Por ello, reconociendo las contribuciones de la pedagogía colombiana al campo, se debe acudir además a un marco de referencia que explicite el espacio biográfico, tal como se identifica en la perspectiva "investigación-formación" desarrollada ampliamente en Latinoamérica por el colectivo BIOgraph de Brasil, entre otros.

El enfoque biográfico de la profesión y del saber docente se inscribe necesariamente en "el carácter dinámico de la construcción de identidad, entendido como interpretación y reinterpretación de experiencias" ${ }^{20}$ donde se sitúa la convergencia del conocimiento disciplinar, el pensar (auto)crítico y el posicionamiento socio-cultural.

Así, en las coordenadas conceptuales de la presente investigación interesa situar el debate de la profesión docente fundada en el saber pedagógico desde la condición socio-cultural y humana de los sujetos de la educación, donde además del saber alimentado por la enseñabilidad de las disciplinas, se reconoce un universo de aprendizajes fundantes en el continuum del vivir. No sólo es el saber como constructo desde el quehacer cotidiano funcional sino desde la cotidianidad existencial, donde el ser mismo es sustrato de interpretaciones. El sujeto de las prácticas pedagógicas es antecedido por el sujeto de la experiencia vital.

En tal perspectiva es fundamental reconocer que el saber docente se (re)construye desde el contexto y la memoria viva. La profesión docente, según se ha dicho, no sólo incluye una base de conocimientos claramente definida sino los referentes sociales que la implican (componente socio-político) y, más inusual aún, el propio carácter interpretativo que comprende el ámbito de producción de sentidos (perspectiva experiencial) indagando "cómo los docentes definen y re-definen su identidad profesional, cómo encaran tanto las reformas como las demandas cotidianas en diversos contextos y situaciones complejas sociales y, sobre todo, si en estas condiciones es posible o no esperar que los docentes sean los catalizadores de la nueva sociedad" 21 .

En la misma línea se destaca también el aporte de Leal y Ferreira, donde al referirse a las instituciones educativas, plantean que en buena medida está en manos del propio docente dejar de percibirse como simple transmisor de conocimientos; no obstante, tanto las instituciones formadoras de maestros como aque-

19 Armando Zambrano Leal, "Naturaleza y diferenciación del saber pedagógico y saber didáctico", Pedagogía y Saberes, no. 50 (2019): 80 .

20 Beatrice Avalos et al., "La profesión docente: temas y discusiones en la literatura internacional", Estudios Pedagógicos XXXVI, no. 1 (2010): 239 .

21 Ibíd. 237. 
llas donde estos actúan, necesitan pasar por cambios significativos en función de ello: “El cambio más determinante es dejar de ser un lugar de simple aprendizaje para convertirse en un espacio de diálogo, de reflexión y de producción de conocimiento, pensando la vida y la sociedad en toda su complejidad; un espacio tanto de diálogo cultural y comunitario, así como de formación permanente del propio docente" 22 .

Por ello vale insistir, desde el marco teórico, en el carácter dinámico e intersectorial de la identidad profesional docente que incluye el modo como los conocimientos, emociones, creencias y significaciones tejidas en contextos socioculturales y educacionales específicos, configuran el ser/quehacer del maestro: "Los docentes pueden considerarse como agentes a quienes se les ha encargado por sobre otras tareas sociales, la tarea de educar y enseñar. Su identidad surge, por tanto, del modo cómo internalizan esta visión, y construyen y reconstruyen significado en torno a ella a lo largo de su vida profesional" ${ }^{23}$.

Así, se entiende la identidad profesional desde un horizonte experiencial ${ }^{24}$ al definirse como "el concepto que los maestros forjan de sí mismos en relación a su profesión y a su trabajo y que se sustenta en elementos referidos tanto a la percepción personal de la enseñanza, como a su percepción de eficacia. Se entreteje en la identidad docente lo que los maestros saben (su base de conocimientos), lo que creen (creencias), lo que sienten (emociones) y lo que interpretan (significaciones); todo ello, marcado por los contextos singulares y globales en los que ejercen su trabajo" ${ }^{25}$.

En consecuencia, el saber docente intrínsecamente asociado a la identidad profesional se ensambla en un complejo proceso de biografización, debido al carácter vital de los aprendizajes, como certeramente expone Maurice Tardif: "Es imposible comprender la cuestión de la identidad de los maestros sin insertarla inmediatamente en la historia de los propios actores, de sus acciones, proyectos y desarrollo profesional [...]. El 'saber experienciado' es un saber temporal, evolutivo y dinámico que se transforma y se construye en el ámbito de una carrera, de una historia de vida profesional, e implica una socialización y un aprendizaje de la profesión" ${ }^{26}$.

Y, así mismo, ese proceso de biografización se hace patente por la naturaleza narrativa de la existencia y de sus registros identitarios (el yo que cuenta la experiencia vivida): “La cognición del docente parece en gran parte interpretativa y lingüística, y no 'computacional': es menos un sistema cognitivo de procesamiento de la información que un proceso discursivo y narrativo enraizado en

22 Conceição Leal da Costa e Ilane Ferreira, "Alteridades (s), escritas de si e reflexão: olhares cruzados sobre a formação de professores em Portugal e no Brasil", Revista Brasileira de Educação de Jovens e Adultos 5, no. 10 (2017): 112.

23 Avalos, "La profesión docente", 239.

24 Como referente de investigación fenomenológica hermenéutica en el campo educativo, véase: Max van Manen, Investigación educativa y experiencia vivida. Ciencia humana para una pedagogía de la acción y la sensibilidad (Barcelona: Idea Books, S. A., 2003).

25 Avalos, "La profesión docente", 238.

26 Maurice Tardif, Los saberes del docente y su desarrollo profesional (Madrid : Narcea, 2004), 81. 
la historia vital de la persona, historia portadora de sentido, de lenguajes, de significados procedentes de experiencias formadoras" 27.

Desde esta clave teórica se puede articular el campo de pedagogía y migración por cuanto establece las dinámicas de la profesión docente en una cosmovisión biográfica que integra trayectorias múltiples de lo humano, las mismas que terminan ejerciendo una inevitable influencia en los modos de ser docente, en sus representaciones simbólicas y en las pautas de desempeño que le resultan asociadas.

\section{Diseño metodológico}

El marco epistemológico amplio que orienta el desarrollo de esta investigación toma elementos del enfoque Historia del presente y de la Historia oral, en clave decolonial, y referidos al método biográfico, en este caso, a la construcción de narrativas de profesores migrantes que comparten sus experiencias de vida.

Dada la variedad de acepciones en la investigación biográfica, es preciso asumir un enfoque de tipo integrativo que considere campos densos de relaciones entre el conocimiento de los fenómenos sociales y la construcción continua de subjetividades. Es en este plano que la investigación basada en historias de vida propone comprender las tramas de significación en torno a los procesos sociales estudiados desde la perspectiva experiencial del individuo.

Un enfoque biográfico de tipo integrativo considera la concurrencia entre la perspectiva etnosociológica basada en las relaciones socio-estructurales (normas, códigos, procesos que estructuran la vida social $)^{28}$ y el abordaje interpretativo centrado en el nivel de significaciones (auto) reflexivas que pretenden transmitir las personas en la producción de sus relatos vitales.

Esta articulación también ha sido sugerida magistralmente por el sociólogo italiano F. Ferrarotti, quien legitima el valor heurístico de los relatos biográficos y proclama su carácter totalizante. En su planteamiento, lo individual y lo colectivo interactúan ineludiblemente constituyendo una praxis sintética entre las experiencias singulares de los fenómenos sociales y los contextos colectivos en los que éstos ocurren ${ }^{29}$.

En esta escala interdimensional se sitúa la valoración de la experiencia y del acontecimiento para la comprensión del presente histórico donde el análisis de la realidad social vigente procura discernir los caracteres fundamentales de la contemporaneidad y restituir el mundo de la experiencia vivida ${ }^{30}$. Estudios biográficos que contribuyen, además, a la configuración sociopolítica basada en la

\footnotetext{
27 Ibíd., 76.

28 Daniel Bertaux, Los relatos de vida. Perspectiva etnosociológica (Barcelona: Bellaterra, 2005).

29 Franco Ferrarotti, "On the Autonomy of the Biographical Method", en Biography and Society: The Life History Approach in the Social Sciences, comp. Daniel Bertaux (London/Beverly Hills: Sage Publications, 1981), 19-27.

30 Julio Aróstegui, La historia vivida. Sobre la historia del presente (Madrid: Alianza, 2004).
} 
relación entre aparatos de poder y sujetos políticos/sociales que transversalizan toda situación o acontecimiento ${ }^{31}$.

En estas coordenadas se inscribe el estudio de la renaciente migración como un escenario societal producto de la matriz modernidad-mundo que la ha consolidado en los últimos años. Al fracturar las ya clásicas relaciones de dominación entre las naciones consideradas "desarrolladas y civilizadas" del Norte global, aparece la mirada decolonial que permite situar epistémicamente la migración en las coordenadas del Sur-Sur afirmando con Lechner y De Brito: "Reconocemos la investigación biográfica y autobiográfica en el estudio de las migraciones como una oportunidad por excelencia de practicar ideales de igualdad y de justicia social en el trabajo académico" ${ }^{\prime 2}$, lo cual aporta una perspectiva decolonizadora del saber y del pensamiento.

Así, los estudios basados en relatos de vida articulados a la comprensión del presente denotan un potencial emancipador basado en el auto-desciframiento del sujeto: "La investigación biográfica, al tomar como centralidad las narrativas de los sujetos sobre sus experiencias singulares, busca revelar los modos propios como viven, narran y aprenden con sus historias de vida, articuladas a los contextos sociales, desvelando en una dialéctica espacio-temporal, movimientos constitutivos de las identidades y hechos biográficos que son inherentes a las experiencias humanas" ${ }^{\prime 33}$.

Finalmente, en la intersección socio-individual y en las claves decoloniales para el análisis del presente, se sitúan las narrativas de los sujetos sobre su experiencia, pues, el proceso de biografización se patentiza en el acto narrativo como registros de identidad que, siendo múltiples, se entretejen como construcción de sentido. Ciertamente, "en la performatividad del poder intrínseco de la historia individual, rescatamos el valor de las experiencias privadas que dan rostro a la historia colectiva y voz a quien participó en ella" ${ }^{34}$.

Resulta fundamental considerar que el proceso de biografización es posible por el carácter histórico del fenómeno humano mismo, por la antropología contingente donde "el sujeto de la experiencia (empírico), de carne y hueso, se caracteriza por situarse en el tiempo delimitado de su existencia, desde el nacimiento hasta la muerte, por constituirse como persona concreta (hombre, mujer, adulto, niño) determinada por su corporeidad, actuando y padeciendo bajo el impacto de normas, leyes biológicas y culturales, sanciones y poder, pero siempre susceptible de reconstruirse y de auto(trans)formar-se continuamente" ${ }^{\prime \prime 3}$. La historicidad, con su sistema de relaciones humanas, de intercambios narrativos y simbólicos, creación cultural y escalas espacio-temporales, es el campo de po-

31 Hugo Fazio, La historia del tiempo presente: historiografía, problemas y métodos (Bogotá: Universidad de los Andes, 2010).

32 Elsa Lechner y Zeila de Brito, "Migrações, pesquisa biográfica e (auto) biográfica: apresentação", Revista Brasileira de Pesquisa (Auto)Biográfica 3, no. 7 (2018): 15.

33 Ibíd., 16.

34 Ibíd.

35 Maria da Conceição Passeggi, "A pesquisa (auto) biográfica: por uma hermenêutica descolonizadora”, Coisas do Gênero 2, no. 2 (2016): 310 . 
sibilidad de la autopoiesis existencial, de la generación permanente de sujeto en un cierto marco de actuación social y política.

Así, se asume la concepción de la producción narrativa como instrumento semiótico asociado a la (re)construcción identitaria que, en el marco de la presente investigación, tiene que ver con la forma como los maestros interpretan los saberes de sí mismos y de sus prácticas a partir de la experiencia migratoria:

La biografización es, por tanto, ese proceso permanente de aprendizaje y de constitución sociohistórica de la persona que narra. La investigación (auto)biográfica privilegia, pues, esos procesos de biografización con el objetivo de comprender cómo los individuos se convierten en quienes son. No se trata, por tanto, de una actitud esporádica o simplemente circunstancial, sino de una dimensión constitutiva de los procesos de individuación y de socialización, estrechamente relacionados con las condiciones sociales en las cuales los individuos se biografían y producen, narrativamente, formas de existencia para sí mismos y para el otro ${ }^{36}$.

\section{Ámbito o alcance de estudio}

El desarrollo de la investigación se llevó a cabo en la ciudad de Tunja, capital del departamento de Boyacá, región central de tránsito entre ciudades principales colombianas de la región andina con alto flujo de migrantes venezolanos. Para efectos de delimitación empírica, el trabajo de campo se organizó desde tres factores centrales que expresan las condiciones de posibilidad para la producción de una narrativa (auto) biográfica:

a) Criterio demográfico. Se buscaron hombres y mujeres venezolanos, en edad laboral productiva, establecidos de forma permanente, transitoria o definitiva, en el territorio nacional colombiano, radicados al momento del desarrollo de la investigación en Boyacá, cuyas razones de movilidad se considerasen inducidas, directa o indirectamente, por la crisis social y política del país de origen.

b) Criterio profesional. Se buscaron profesionales en ejercicio docente regular en su país de origen en cualquier área del conocimiento y en cualquiera de los niveles educativos formales (preescolar, básica, media o superior) o no formales; y que se encontrasen actualmente en desarrollo de la docencia, de cualquier actividad económica aun de tipo informal o sin desempeño laboral específico.

c) Criterio de conveniencia programática. Entendiendo que en el desarrollo del proyecto biográfico hay una "exposición del yo", que debe ser cuidada e informada, se privilegió la condición de profesores/as voluntario/as que aceptaran contar y hacer públicas sus experiencias de migración en Colombia y cómo estas han movilizado sus historias de vida. Por lo tanto, solo podrían participar quienes, a través de la aceptación del consentimiento informado, manifestasen interés efectivo en construir con los pares e investigadores un conocimiento de fundamento biográfico. Dicho consentimiento aborda el sentido de la investi-

36 Maria da Conceição Passeggi y Elizeu Clementino de Souza, "O Movimento (Auto) Biográfico no Brasil: Esboço de suas Configurações no Campo Educacional”, Revista Investigación Cualitativa 2, no. 1 (2017): 9. 
gación de manera compartida y colaborativa, así como la divulgación de los productos obtenidos con fines estrictamente académicos y sociales.

El rastreo de población ajustada al perfil del proyecto se realizó durante varias semanas por redes sociales en internet, especialmente en los grupos de venezolanos en Boyacá; por anuncios en la Red Colombia Migra dirigida por el experto en temas migratorios, William Mejía; y, mediante el apoyo de la Fundación Cultural Simón Bolívar liderada por la señora Anny Uribe Táriba, en la ciudad de Tunja, quien cuenta con una amplia base de datos de la colonia venezolana en el departamento.

Dado que los tres criterios en su conjunto cumplen un papel de estricta selección poblacional, se logró disponer de ocho elegibles de los cuales solo dos maestras de educación básica cumplieron finalmente el requisito de factibilidad operativa y concretaron su participación. En este trabajo se da cuenta del caso de la profesora Narvelis Elizabeth Rondón Araujo.

\section{Recolección de información}

De común acuerdo con la maestra participante, se preparó la producción de un relato oral amplio por medio de entrevista, concretamente, bajo el formato de la entrevista biográfica seriada que contempla el conjunto de entrevistas desde cierta unidad de significación. Además, al cierre del proceso, se invitó a otra de las maestras elegibles para realizar una versión exploratoria de taller biográfico simultáneo. Todo el proceso de recolección de información fue realizado entre abril y junio de 2018.

Para la preparación del relato biográfico oral se aportaron cuatro pautas orientadoras que cumplen funciones de categorías anticipatorias de la investigación, es decir, se adecuó el desarrollo del objeto de estudio desde la acción de los sujetos participantes a partir de los siguientes ejes constitutivos:

a) Llegar a ser un maestro. Este eje trata el surgimiento de la vocación docente y el proceso de formación profesional, incluyendo el establecimiento de creencias y comprensiones fundacionales que rigen la práctica magisterial.

b) Maestros en ejercicio. Aborda las etapas o momentos de la carrera docente desde las trayectorias mismas del sujeto, sus aprendizajes, confrontaciones y desarrollos en perspectivas de espacio-temporalidad.

c) Migración y pedagogía. Constituye el relato autobiográfico de la migración propiamente dicha, destacando el proceso migratorio como "acontecimiento precipitante" (turning points o recordações referênciais) y sus afectaciones en el ámbito personal, familiar, laboral y comunitario.

d) Memoria y porvenir. Es la dimensión proyectiva que implica la reinvención de los modos de trabajo, es decir, el (nuevo) quehacer cotidiano, los sentidos, ideaciones y realizaciones que, como producto de la migración, se integran a nuevas cosmovisiones de mundo y de educación. 
De igual manera, según fue mencionado, se implementó un ejercicio de Taller Biográfico o "círculo de historias" ${ }^{37}$ el cual explicita el formato cooperativo de la investigación revelando "una investigación compartida y colaborativa en la cual los propios migrantes participan no como sujetos de estudio sino como sujetos en la investigación" ${ }^{\prime 38}$. Este postulado esclarece la dimensión relacional del estudio biográfico donde interactúan subjetividades, fenómenos sociales y experiencias de vida más allá de un modo objetivista de comprender la acción humana.

La afectación experiencial de los participantes es una de las bases de este ejercicio de investigación biográfica que activa el papel del sujeto no solo frente a la investigación en sí misma sino en la preparación de un nuevo modo de participación social más allá de la invisibilidad y el silenciamiento.

El taller se llevó a cabo el 27 de junio de 2018 tomando en cuenta los criterios desarrollados por Lechner pero realizando algunos ajustes de acuerdo con la participación de las dos maestras migrantes. En todo caso se quiso propiciar la producción de narrativas biográficas mediante ejercicios de escucha de las participantes y se permitió la socialización de los relatos propios (verbalización de la experiencia) a la manera de una red de la palabra. De esta forma, se manifiesta el principio de resonancia o refracción temática por el cual cada participante verbaliza reflexividades a partir de la narración del otro; se exteriorizan comentarios ante la experiencia ajena como resonancia sensible producto de la escucha atenta. En el proceso, los oyentes de cada intervención toman la palabra para expresar cómo asimiló la historia del otro, identificando en conjunto subtemas manifiestos que van configurando una experiencia común ${ }^{39}$.

\section{Hallazgos, análisis y discusiones ${ }^{40}$}

\section{Horizontes comprensivos del ser docente}

La primera categoría del estudio recoge la exploración en torno a los elementos fundacionales de la profesión docente. En el desarrollo de la narrativa biográfica se encuentra, en primer lugar, un sentido de aprendizaje continuo en la experiencia de llegar a ser una maestra que, si bien se activa a partir de unos momentos pretéritos específicos, se extiende hasta el momento actual marcado

37 Elsa Lechner, coord., Rostos, Vozes e Silêncios. Uma pesquisa biográfica colaborativa com imigrantes em Portugal (Coimbra: Almedina/CES, 2015).

38 Ibíd., 24.

39 Ibíd., 38.

40 La presentación de los resultados se integra con el análisis del investigador, dando prevalencia al producto narrativo constituido. Por ello se permite que emerja la voz de la maestra en los sucesivos apartados teniendo en cuenta que no son fragmentos textuales aislados sino unidades de sentido completo que hacen parte del horizonte interpretativo del relato total. De este modo florece el relato de sí que acontece en un cierto marco socio-cultural configurador de subjetividades: "Desde la posición de las pedagogías liberadoras, la narración es una construcción biográfica e histórica, sobre sí mismo y sobre el mundo". José Ignacio Rivas, "El ser humano como narración histórica: aprendiendo desde la acción”, Diálogos. Educación y formación de personas adultas 3, n.os 75-76 (2013): 26. Este es el potencial de la investigación biográfica por aquello que dice del sujeto y por lo que dice de la historia habitada por él. 
por las coyunturas de la movilidad, las cuales conducen las concepciones que la maestra migrante atribuye a la educación.

Tabla 1. Categorías emergentes. Genealogías y saberes pedagógicos de la maestra migrante

\begin{tabular}{|c|c|c|c|c|}
\hline \multicolumn{5}{|c|}{ SABER DOCENTE-MIGRATORIO } \\
\hline \multirow{2}{*}{$\begin{array}{c}\text { RELACIÓN } \\
\text { EXPERIENCIAL } \\
\text { CON EL } \\
\text { CONOCIMIENTO }\end{array}$} & \multirow{2}{*}{$\begin{array}{c}\text { Formación } \\
\text { del carácter } \\
\text { ético-moral } \\
\text { del individuo }\end{array}$} & \multirow{2}{*}{$\begin{array}{l}\text { Formación } \\
\text { práctica del } \\
\text { maestro: } \\
\text { profesión- } \\
\text { condición }\end{array}$} & $\begin{array}{c}\text { Sentido crítico } \\
\text { y articulación } \\
\text { política }\end{array}$ & \multirow{2}{*}{$\begin{array}{l}\text { Transformación } \\
\text { cultural y } \\
\text { perspectiva de } \\
\text { retorno }\end{array}$} \\
\hline & & & $\begin{array}{c}\text { Movilidad } \\
\text { social regresiva }\end{array}$ & \\
\hline
\end{tabular}

Fuente: Elaboración propia.

Se pueden resaltar algunos elementos genealógicos - en sentido biográficoque preparan la situación actual de la educadora. La maestra Narvelis es licenciada en Educación Integral por la Universidad Nacional Experimental de las Fuerzas Armadas, núcleo Trujillo (2014); sin embargo, en su narrativa biográfica se percibe un marco de intencionalidades cruzadas que caracterizan el proceso mismo de la formación docente pues, aunque podría inferirse una posición heredada del magisterio por vía materna, la búsqueda fundante de la maestra se deriva de un talento particular de tipo deportivo:

Tengo contacto con lo que es la educación porque mi madre es educadora. Mi mamá siempre me inculcó lo que es la educación y la lectura. Desde muy pequeña tuve ese interés en la lectura, en querer aprender y ese tipo de cosas, pero la educación no fue mi prioridad en el sentido de estudiarla. Yo nunca me vi como profesora, mi inclinación siempre fue por el deporte, mi objetivo era estudiar Educación Física ${ }^{41}$.

En la conquista del ideal propio se va constituyendo un itinerario de incertezas, por un lado, como bachiller mercantil que comienza a cursar la carrera de Contaduría Pública en la Universidad de Los Andes-Trujillo, pero, al mismo tiempo, como deportista de alto rendimiento, que llega a ser representante de la selección del Estado y de la selección nacional de Venezuela. Entre las exigencias del estudio universitario y del entrenamiento deportivo, hacia la mitad de la carrera, surgen ciertos cuestionamientos que comienzan a socavar la lógica lineal de un proyecto de vida diseñado en torno al mundo empresarial:

Cuando estoy en Contaduría Pública, en el quinto semestre, ya empezaban las materias más fuertes, y yo me siento un día y digo: ¡No me llena! Yo me veía como profesional, como licenciada en Contaduría Pública, sentada en un escritorio, haciendo... balances y todo eso, muy bien, con la vestimenta y todo lo demás, porque uno dice, un ejecutivo, jlo máximo!, las grandes empresas y todo eso, pero había algo dentro de mí que me decía que no me iba a llenar ${ }^{42}$.

41 Entrevista 1 a Narvelis Rondón, Tunja, 16 de abril de 2018.

42 Ibíd. 
La combinación del mundo de los negocios y del ámbito deportivo va cediendo terreno a la vocación pedagógica oculta en la naturaleza misma de la formación deportiva. Realmente es el contacto previo y la búsqueda de profesionalización deportiva de alto rendimiento, el primer factor motivador de la ruptura con el mundo de los negocios:

Llega a nosotros la posibilidad de estudiar en la Universidad Nacional Experimental de las Fuerzas Armadas, y a mí me la vendieron así, o sea, "estudie un semestre educación integral, porque el próximo semestre vamos a abrir Educación Física". Yo dije, imi sueño realizado! Entonces ahí es donde incursiono yo en la parte de Educación, en la educación integral como tal ${ }^{43}$.

El deporte cumple una función sustancial de nuclearización del proyecto de vida, concentra lo disperso y alimenta una línea de sentido. Es dentro de esa exploración que se cifra y se establece la vocación docente como parte de una búsqueda asociada al ejercicio profesional de la carrera deportiva donde el espacio de la "educación integral" solo cumple un efecto transicional hacia lo verdaderamente deseado; sin embargo, es en tal coyuntura donde emerge la posibilidad de rediseñar opciones desde una articulación complementaria de intereses y expectativas: ¡desde el deporte sería posible ser maestra!

Así, en el postergamiento de la promesa del nuevo programa profesional de Educación Física en la universidad, será una oportunidad de práctica deportiva la que permita apreciar una inesperada potencialidad pedagógica:

Cuando llega la parte de que yo estoy trabajando en una cancha sintética por la parte de deporte, íbamos a abrir un proyecto, la cancha estaba nueva, íbamos a abrir un proyecto e incursionar, o sea, llevar a los niños a la cancha, para que los niños vieran todas las actividades [...] entonces, yo lo que quería era dar lo que yo sabía que era la parte deportiva, como entrenadora, y va y me ponen allá de entrenadora principal y comienzo... a enseñar. A enseñar lo que yo sé, pero a enseñar, ique es una palabra muy grande! Entonces, cuando uno se da cuenta que uno puede... influir en un grupo de personas, de personitas, porque... son niños, y uno puede influir tanto positiva como negativamente en alguien, ahí es cuando uno se da cuenta, esto no es tan fácil como uno lo ve. Y bueno, ese plan vacacional fue enriquecedor porque me cambió la perspectiva total de lo que era la educación. Me cambia ese sentido ${ }^{44}$.

De esta forma, el momento genealógico inicial se caracteriza por la paradoja y la incertidumbre donde el magisterio aparece como opción fundamental, no lineal sino multilateralmente, constituida en torno a un núcleo prevalente fundado en el ámbito deportivo. Así lo entiende la maestra: 
Yo me acuerdo tanto de un partido que yo estaba dirigiendo a mi equipo, a los niñitos, y yo estaba tan feliz, tan feliz de que ellos hicieran lo que yo les había enseñado durante toda una semana, hicieran algo así, me decían "prof, prof", y todos alegres... o sea, yo dije, esto es lo que yo quiero hacer, porque uno como tal tiene tantas experiencias, por lo menos en la parte deportiva, lo enseñan tanto a uno a cómo manejar sus emociones, uno vive tantas decepciones, tantos triunfos... Yo dije, esto es lo que yo quiero hacer. Y ahí es donde yo entré a mi carrera, yo voy a seguir y voy a seguir porque... uno tiene un propósito en esta vida. Tal vez no sea hacerse rico, todos quieren eso, pero si uno puede influenciar positivamente en la vida de alguien, pues está... haciendo su cometido aquí en la vida, aquí en la tierra, ¿me entiende? Y por eso es que yo me enamoré de la educación $n^{45}$.

En el propósito de influir positivamente en la vida de alguien, se anticipa una intencionalidad ética volcada a la formación del sujeto. La vocación docente se manifiesta, entonces, como vocación de humanidad: "ser profesor no es labor de solamente unas horas; es constante, tiene que estar influyendo todo el tiempo" 46 .

Dentro de las concepciones que la maestra migrante atribuye a la educación se pueden identificar las siguientes subcategorías: en primer lugar, el cultivo de la fortaleza interior, esto es, una templanza deportiva que asocia resistencia física con fortaleza espiritual orientada a la configuración del carácter moral del individuo:
Uno ve el deporte y pensaría que es "no, mire vaya ahí y dele patadas al balón; vaya corra y..." No. Uno cuando se para a trotar, uno tiene que tener una voluntad que solamente la pasión de uno, o la disciplina, lo impulsa a uno. Porque uno somete el cuerpo a momentos muy difíciles. Si tú te paras en una pista y ves a un atleta darle vueltas y vueltas, te imaginarás, qué piensa esa persona, está loco, que le da tantas vueltas a la pista y no se cansa, cuál es el fin de eso. Y el fin es que uno siempre está pensando: "yo puedo, no te rindas, sigue adelante". Uno se mete una psicología en la cabeza y siempre, "una vuelta más, esta sí termino... otra vuelta que usted puede, vamos que sí". Así pasa en el deporte, entonces te forma un carácter como tal. Y eso me ha ayudado mucho en esta parte de migración porque son muchos aspectos difíciles... y más que todo el psicológico, el emocional... le da a uno durísimo ${ }^{47}$.

El cultivo de la fortaleza interior como acto pedagógico implica preparar el afrontamiento personal para las situaciones-límite, pero ello solo es posible desde una perspectiva docente implicada en las realidades humanas. De esta manera, se da una nueva dimensión a la opción vocacional del maestro: hacer que otros también descubran un sentido vital enraizado en el valor de lo adquirido y en la potencialidad de lo intercambiado. Así, en la concepción pedagógica de la maestra migrante se revela una relación experiencial con el conocimiento enseñado que repercute directamente en los alcances de su relevancia práctica. 
Es preciso notarlo en la forma como se describe la eficacia de la formación pedagógica universitaria que intenta conectar, de alguna forma, conocimiento especializado y situacionalidad profesional del sujeto-docente:

\begin{abstract}
El fin principal de la educación es llevar un conocimiento significativo a esa persona - a esa personita - y que sea algo que lleve en sí, o sea, que lo analice, que lo interiorice, y que él pueda utilizarlo más adelante [...]. Los conocimientos que uno adquiere en la universidad como tal no son tan significativos como ir a dar clase, y yo creo que la parte en la que se enfocó la universidad fue esa: "vaya y aprenda dando clase". Porque nosotros tuvimos que hacer proyectos sociales, estar muy inmersos en el mismo campo laboral y eso es lo que marca la diferencia: que no es tanto libro... ${ }^{48}$.
\end{abstract}

El concepto de relevancia práctica de la educación comienza en la formación misma de los maestros requiriendo una perspectiva fundada en escenarios profesionales de desempeño y encuentro interpersonal. Es en ese orden de ideas donde la experiencia migratoria se convierte en un texto pedagógico para la formación humana pues, más allá de las convenciones temáticas, la fuerza vinculante de lo vivido conduce a una resignificación permanente de las visiones de mundo. Tales componentes se aprecian en la declaración narrativa donde se muestra el aprendizaje como una realidad transicional en cuyo movimiento se desvirtúan las creencias paradigmáticas frente a un modo alterno de ser docente:

\begin{abstract}
Pero todo ha sido un aprendizaje - yo digo - en el momento donde yo vuelva a ejercer va a ser... uno tiene otro tipo de perspectiva, inclusive cuando estaba trabajando en Yopal, yo trabajaba con toda la... allá yo daba Educación Física, daba artes plásticas, daba varias... daba recreación; yo les hacía muchas actividades recreativas y todo, y yo les hablaba de esto: "mira, ¿sabes qué es difícil?, no tener a los padres, tienes que valorarlos; ¿sabes qué es difícil? No tener a tu familia cerca, tienes que valorarla", o sea, en medio uno de su ejercicio como docente, les va dando experiencias de vida pero enmarcadas en los valores ${ }^{49}$.
\end{abstract}

En complementariedad con estas dimensiones, se halla finalmente el vector de transformación cultural con perspectiva de retorno basado en una interacción política vinculante. En efecto, toda la naturaleza ética que constituye el telos del hecho educativo, ocurre en un marco de actuación política. Implica siempre un escenario de relaciones inter-humanas que aportan el conocimiento de los contextos locales, de las comunidades situadas, de sus subjetividades y de la forma como se tejen vínculos para la constitución del Estado. En consecuencia, de la educación ética se deriva la formación política la cual se basa en un criterio amplio de la vida social, en el conocimiento de la realidad con sentido histórico y en la afectación palpable de sus implicaciones en el presente. La narrativa de 
la maestra hace alusiones en este sentido cuando se cuestiona cómo hablar de los actores de la política a las personas en formación:

Uno tiene que partir de un pensamiento crítico. Uno no puede decirle a alguien "este es el bueno", uno tiene que enseñarles a los niños y a los adolescentes que tienen que investigar quiénes son esas personas, tienen que hacer un análisis de ese tipo de personas y ver en la historia, porque es que uno no se puede guiar solamente con lo que me dicen ahorita, sino ver la historia ${ }^{50}$.

En la noción de historia sugiere el papel de la memoria, para controvertir una eventual percepción determinista del hecho político que desconoce antecedencias y consecuencias. Por eso es importante la consolidación de una pedagogía orientada a la crítica antes que a la reproducción ideológica.

En esta misma secuencia reflexiva aparece el cuestionamiento a las relaciones de poder ejercidas por el ente gubernamental sobre el ejercicio educativo que, en el marco amplio de un análisis migratorio, cobra especial interés. Cuando la maestra rechaza la interferencia de una directriz de gobierno sobre la orientación de su monografía de licenciatura, plantea el problema de la colonización política de la educación que, en cualquier caso, puede adoptar múltiples matices y expresiones:

Cuando yo estaba estudiando en la universidad yo tuve un problema con mi tesis [...] resulta que el título de mi tesis tenía que ir con una referencia a los valores de la patria de Chávez... tanto lo recuerdo porque me dio mucha rabia, porque ahí es donde yo me dije "la educación aquí está perdiendo sus valores", ¡cómo me van a decir en una universidad que mi título de tesis tiene que ir afín a algo político! ${ }^{51}$.

En las manifestaciones del control directo del Estado hacia las intencionalidades educativas, la maestra advierte que una educación bajo mecanismos de control ideológico, pierde los valores centrados en la persona, comenzando por el ejercicio de la autonomía y la creatividad: "Yo digo que uno como docente tiene que ser muy autónomo en su pedagogía, en su manera de enseñar, en su manera de aprender, muchas cosas, uno tiene que ser muy... muy original" ${ }^{52}$.

Sólo desde una especial conexión con las realidades sociales y políticas, con la manera de comprenderlas y, sobre todo, de vivirlas, el migrante descubre, desde un enfoque positivo de su desarraigo, la perspectiva de retorno como transformación. En el análisis de la profesora Narvelis, quien ha sido forzada a salir de su país, puede retornar a él de una manera nueva, capitalizando el conjunto de las situaciones vividas y de las enseñanzas adquiridas desde una visión integradora de los problemas locales: "Yo digo que la mayor parte de los venezolanos que estamos acá soñamos con volver a Venezuela; pero no solamente volver a 
ser lo que éramos antes sino volver de otra manera. Ese es el sueño del venezolano, ese es el sueño que tenemos ahora" ${ }^{53}$.

Ya en la perspectiva específica del maestro migrante, aparece aquí un especial enfoque de preocupación social para contribuir a la formación de nuevas generaciones con una perspectiva plural del mundo desde un patrimonio ético fundamental en el ejercicio de todas las profesiones. Podría plantearse, así, el sentido de una educación para la transformación cultural de las generaciones enfocada en la manera de asumir los oficios desde un sistema de valores que abarca la integridad moral y la pasión por aquello que se realiza: "Si no hay educación no hay médicos, no hay ningún otro tipo de profesión; y si no hay unos buenos educadores no va haber unos buenos profesionales dando el conocimiento, o impartiendo, no conocimientos, sino las pasiones..."

Muy importante resulta el tema de la pasión profesional porque ello previene el auge de la corrupción en las prácticas sociales. El maestro que comparte el empeño por una vocación socava, desde su ámbito de intervención, los mecanismos que sostienen la degradación de las sociedades. La integralidad ética en el ejercicio profesional se deriva de la autenticidad del proyecto de vida:

Uno como ser humano tiene que buscar esa pasión, que en la universidad no te la van enseñar, te van a decir cuáles son los caminos más regulares, las carreras que son más lucrativas, eso es lo que te enseñan, aquellas que son más factibles por el lugar donde estás ubicado, todo eso... pero no. Uno la línea que debe seguir es la línea de su corazón, de lo que lo apasiona hacer a uno, de lo que lo va hacer a uno emprender cosas maravillosas que ni uno mismo piensa que va a lograr hacer. Solamente esa línea es la que te va a conducir al éxito, lo digo porque en la parte deportiva es así. Yo soy portera, guardameta, y para mí eso ha sido también un aprendizaje [...]. Cuando uno hace algo por vocación, lo hace con ética ${ }^{55}$.

Esta preparación de las disposiciones personales para asumir el oficio docente se articula con otras categorías asociadas al desarrollo profesional en escenarios de ruptura. En primer lugar, encontramos el mandato práctico de la diversificación ocupacional debido a que la migración conlleva desplazamientos de campo laboral impelidos por las circunstancias mismas del desarraigo. El profesional de la educación, al igual que otros profesionales, puesto en estado de excepcionalidad laboral ante la urgencia de satisfacción de las necesidades básicas, asume un quehacer fortuito que usualmente lo aleja de sus áreas tradicionales de desempeño.

Así se identifica en la historia particular de la maestra Narvelis quien, al momento de participar en esta investigación, no se desempeña en el campo educativo como docente, aunque en la primera etapa de su establecimiento en Colombia sí tuvo la oportunidad de hacerlo. Sin embargo, esos desempeños en

\footnotetext{
53 Ibíd.

54 Entrevista 3 a Narvelis Rondón, Tunja, 24 de abril de 2018.

55 Entrevista 1 a Narvelis Rondón, Tunja, 16 de abril de 2018.
} 
instituciones escolares de Yopal y Tunja - para las áreas de Educación Física y suplente en el nivel de pre-jardín, jardín y transición - se caracterizaron por su fugacidad e inestabilidad debido, ante todo, a las exigencias de contratación laboral para extranjeros venezolanos y las dificultades para reunir en tiempo y modo los distintos documentos que les son solicitados. La valoración de los pocos oficios docentes asumidos en Colombia parte de contrastar la formación docente en su país de origen con las nuevas responsabilidades asignadas, percibiendo las falencias de los sistemas educativos y la necesidad de cualificar continuamente la preparación profesional de los educadores ante los desafíos que plantea la actual generación de estudiantes.

La movilidad social regresiva es una digresión con el orden de expectativas profesionales dispuesto por el individuo como conjunto de proyectos intencionados dentro de un marco de espacio y tiempo determinado. El migrante pierde el control de sus escenarios de actuación laboral, los cuales salen de la esfera proyectiva intencionada para situarse en un punto de extrema necesidad por la generación de ingreso y satisfacción de carencias inmediatas. Ello puede conjugarse, según la disposición de cada persona, con una suerte de recuperación de otras opciones de vida como forma de aprovechamiento del estado fortuito de situaciones. En el caso de Narvelis, sus desempeños actuales se mueven entre la actividad deportiva profesional, el estudio de un programa técnico de Salud Ambiental, la venta de manuales de interés histórico y turístico en el Puente de Boyacá; y, la colaboración en negocios de alimentación junto a otros compatriotas.

Tal dinámica la hace proclive a la movilidad social, como se puede apreciar en la valoración de trayectoria que oscila entre la indeterminación de prácticas docentes iniciales y la necesidad de ocupaciones diversificadas:

Todo ha sido un reto porque cuando uno sale recién graduado uno no sabe a qué se enfrenta, cuáles son sus cosas, uno piensa "yo estudié esto y esto es lo que voy a hacer", si hubiese ejercido en mi país pues uno se limita, uno dice "yo estudié esto y esto es lo que voy a desempeñar y ya no incursiono en otros ámbitos", pero cuando tú sales de tu país tú ya no tienes opciones sino hacer lo que hay que hacer. Ya tú no mandas sino el que manda es el entorno, entonces tú tienes que adaptarte ${ }^{56}$.

Pero tal adaptación, siendo un mandato social, no se entiende como una acepción inercial. Por el contrario, conlleva la exploración del campo propio de dominio para el despliegue de potencialidades donde el sujeto-maestro se interpreta como actor de cambio. El profesor migrante integra a su saber pedagógico un dinamismo de prácticas basado en el cultivo constante del conocimiento, desde sus múltiples posibilidades, y en una relación de humanidad con los otros:

Uno, en la medida en que va desarrollando su actividad como docente, uno tiene que ir innovando, actualizándose, ser... que uno investiga, que uno mismo tiene

56 Entrevista 2 a Narvelis Rondón, Tunja, 18 de abril de 2018. 
que ir aprendiendo por su cuenta: autodidacta. Porque uno a veces piensa que debe tener muchos títulos para tener peso académico, y no tiene que ser así. Porque a veces uno no tiene los recursos para aprender [...]. De eso se trata, no son solamente títulos académicos, son experiencias y conocimientos que se pueden dar ahít7.

La oportunidad dentro de la ruptura será una característica recurrente del proceso migratorio de la maestra. La misma participación como testimoniante principal de esta investigación y el compartir de su experiencia en el Coloquio Internacional Migración y Pedagogía, celebrado en la Universidad Pedagógica y Tecnológica de Colombia el 11 de octubre de 2018, da cuenta de las inusitadas dimensiones de la relación social y profesional derivadas de la reidentificación del migrante frente a su comunidad de connacionales y la incidencia en órdenes académicos de formación permanente dentro del territorio de destino.

Saberes desde la experiencia migratoria de la maestra

En este apartado se quiere resaltar el campo de significación de la experiencia migratoria en sí misma para las distintas atribuciones que la maestra va recomponiendo sobre el ejercicio personal, social y profesional de la educación.

Tabla 2. Categorías emergentes. Saberes fundados en la experiencia migratoria de la maestra

\begin{tabular}{|c|c|c|c|c|}
\hline \multicolumn{2}{|c|}{ SABER MIGRATORIO } \\
\hline & & Restaurar & $\begin{array}{c}\text { Expectativa de } \\
\text { progreso }\end{array}$ & $\begin{array}{c}\text { Migración, } \\
\text { alteridad y } \\
\text { memoria }\end{array}$ \\
\cline { 3 - 5 } $\begin{array}{c}\text { DIALÉCTICA } \\
\text { ARRAIGO- }\end{array}$ & $\begin{array}{c}\text { Causalidad } \\
\text { DESAmulativa }\end{array}$ & $\begin{array}{c}\text { Rertad de } \\
\text { elección }\end{array}$ & $\begin{array}{c}\text { Movilidad } \\
\text { social regresiva } \\
\text { y dignidad del } \\
\text { trabajo }\end{array}$ & $\begin{array}{c}\text { Migración } \\
\text { Sur-Sur }\end{array}$ \\
\hline
\end{tabular}

Fuente. Elaboración propia.

Como se aprecia en la Tabla 2, el conjunto de la dinámica que rodea el desplazamiento transfronterizo se estructura en torno a la dialéctica arraigo-desarraigo $^{58}$. La maestra se sitúa en una tensión constante entre el círculo directo de relaciones afectivas, tejidas en el contexto constituyente donde se desarrollan sus identidades sustantivas, y las coacciones socio-políticas que, de manera paulatina, van creando un estado de inviabilidad práctica para el desarrollo comunitario y personal:

57 Ibíd.

58 La dialéctica arraigo-desarraigo como constitutiva de los procesos migratorios puede documentarse en Norbert Elías y John L. Scotson, Establecidos y marginados. Una investigación sociológica sobre problemas comunitarios (México: Fondo de Cultura Económica, 2015); y Abdelmalek Sayad, La doble ausencia. De las ilusiones del emigrado a los padecimientos del inmigrado (Barcelona: Anthropos, 2010). 
Yo no me quería ir de Venezuela, yo no me quería ir, yo estaba... yo me sentía tan bien porque estaba con mi familia, estaba con mis amigos; aunque todo había cambiado no era la misma alegría que uno vivía antes, pero estaba con los que me quieren, ¿me entiende?, y uno así pues afronta cualquier situación [...]. Pero yo no me quería ir, no me quería ir de Venezuela, incluso con esta situación a mí me costó mucho salir y eso que ya había salido antes, había ido, pero me costó mucho ${ }^{59}$.

El señalamiento reiterado del "alto costo" humano que implica la migración es una manera de hacer explícito el profundo sentido de despojo conexo a la partida forzosa, que no solo es una pérdida de bienes, espacios y socialidades, sino una pérdida de sí misma. A pesar de las ausencias recurrentes del vínculo familiar en razón de su actividad deportiva nacional e internacional, el proyecto migratorio evidencia una ruptura fundamental pues no se trata solo de un distanciamiento de ocasión, aun como parte de un proyecto personal de vida, sino como una decisión forzada por las circunstancias que fractura la unidad de los lazos afectivos, siendo esta la entidad más íntima en la armonización integral de la persona:

Porque cuando uno sale por primera vez, uno la emoción de ir, conocer, entonces no le pega tanto la familia porque bueno, yo los veo, los vuelvo a ver en tanto tiempo. Pero cuando uno sale y se encuentra que no sabe cuándo los va a volver a ver, y no sabe qué pueda pasar... y cuando tú estás en momentos difíciles que los extrañas... que quieres abrazarlos... entonces cuando tú vuelves a Venezuela y sientes otra vez ese calor... tú dices prefiero aguantar hambre acá que estoy con mi familia, por lo menos puedo ayudar en algo, ahí otra vez... entonces es una confrontación de emociones muy fuerte porque uno cuando llega otra vez y cree que puede hacer algo, se da cuenta que no, que está atado de manos y pies, que no vas a avanzar tampoco, que no puedes ayudar a tu familia porque apenas estás sobreviviendo tú también ${ }^{60}$.

Ese doble movimiento entre el "no querer irse" y el tener que hacerlo radicaliza la sensibilidad de lo vivido, marcado ya por el impacto de la separación de personas, el abandono de proyectos y el sustituto de patrones culturales identitarios. En último término, la coacción de las circunstancias se impone sobre las raíces afectivas vinculantes mediada por una circunspección de oportunidades en cuya base se combina el carácter personal y el sentido proyectivo de familia. En otras palabras, son los vínculos emocionales los que más dificultan la partida de casa, pero, paradójicamente, son ellos mismos los que, aunados a ciertas condiciones propias del carácter personal, terminan alentando la búsqueda de otras alternativas: "Sin embargo el espíritu de uno, de querer algo más, de que uno no puede ser conformista, de que uno quiere cosas para su familia, ese espíritu empieza uno como a chocar con toda la realidad que está pasando en Venezuela, a chocar y a chocar, y te hace ir" $^{\prime \prime}$.

59 Entrevista 3 a Narvelis Rondón, Tunja, 24 de abril de 2018.

60 Ibíd.

61 Ibíd. 
Los efectos humanos de la dialéctica arraigo-desarraigo son tan radicales que la maestra les da el sentido de muerte como expresión sustantiva de la ruptura. Así se comprende el postergamiento de la salida, orientado a una suspensión intencionada del tiempo como queriendo salvaguardar la excepcionalidad del encuentro familiar: "Cada día que pasaba con mi familia era único, o sea, como cuando te vas a morir, ¿qué puedes hacer tú si supieras que dentro de dos días te vas a morir? Entonces es algo que pasa como ¿qué vas a hacer tú con tu familia si dentro de dos días vas a viajar y no sabes cuándo vuelves? Yo siempre comparo eso de los viajes como cuando uno muere y renace, cada viaje ha sido eso morir, quemar una etapa y otra" ${ }^{62}$.

Ahora bien, ¿qué se encuentra en la base de esa salida tan indeseada como inminente? En el conjunto del relato de la maestra se encuentra una acumulación de causas del orden político nacional que fueron involucrando, de manera directa, la sostenibilidad del núcleo familiar. De alguna forma, se encuentran aquí patrones coincidentes con los registros periodísticos que aluden estados progresivos de crisis, pero desprovistos de las ideologías partidistas para dejar que la construcción biográfica hable por sí misma. Desde esta clave, lo vivido por la migrante no es estadística, ni publicidad, ni oposición al oficialismo, es simplemente biografía.

La situación más determinante es la constatación del deterioro en amplitud de ámbitos. Luego de cada regreso de sus gestas deportivas, Narvelis va percibiendo en su país, en su ciudad, en su comunidad, un estado continuo de detrimento económico, cultural y, peor aún, humano: "En mi casa todo se deterioró, a mí me impactó eso, todo estaba deteriorado, todo estaba como si la pobreza hubiera caído no tanto en el país, en la economía, sino en la vida de las personas... eso a uno lo traumatiza" ${ }^{\prime 3}$.

Desde su perspectiva, ese deterioro se hace patente en la carencia de bienes y servicios, por un lado; y en el auge de vías ilícitas en el esquema amplio del Estado, que comprende la ejecución pública y la búsqueda de formas alternas de toda índole para la sobrevivencia ciudadana. Uno de los contactos directos de la maestra con el escenario de conflicto venezolano es el detrimento del ambiente comercial percibido en los negocios de su padre, quien por años trabajó en la industria del chimó, pero ante la pérdida de prerrogativas laborales adquiridas, terminará dedicándose a la venta de harina y otros alimentos, justo en tiempos de paulatina escasez.

En efecto, el desabastecimiento de alimentos, productos y bienes básicos se irá haciendo notable en el contexto propio en contraste con las realidades de otras naciones vecinas cuando la representación deportiva permitía asistir y entrar en contacto con esos escenarios aprovechables desde todas sus posibilidades: "Nosotras cuando íbamos a algún juego [en el extranjero], pues había mucha comida, esa comida uno no la come en Venezuela, entonces, todo mundo co- 
miendo, nos llevábamos los dulces, las galletas, porque la idea de uno era llevar lo que más podía para Venezuela y también los jabones de baño, los champús y los acondicionadores esos pequeñitos, uno llenaba su maleta con todo eso, para llevar a sus casas porque eso era lo único que podía llevar"64.

De igual forma, la carencia de medicamentos hará perentoria la búsqueda de alternativas para adquirirlos haciendo uso de las redes sociales en internet o incluso reactivando antiguas formas cambiarias como el trueque: "Las medicinas uno las ponía en el Facebook 'necesito tal' y empezaba uno a buscar, uno se conectaba con gente que ni conocía para poder conseguir una pastilla porque ya uno no podía ir a la farmacia y conseguir la pastilla porque no existía, eso ya no existe allá, o sea, uno tiene que ir, hacer un intercambio, buscar a la persona 'mira, estoy donando esto, estoy vendiendo esto, te lo cambio por esto, te lo cambio por lo otro', un sistema de trueques" 65 .

Por su parte, el panorama de acentuación de un estado social crítico se refleja en un sistema de ilegalidad que adopta múltiples mecanismos de evasión de la ley, los cuales pueden encontrarse en las mismas corporaciones del Estado llamadas a velar por su cumplimiento. Llama la atención cómo el comercio de alimentos se llega a convertir en una actividad "ilegal" perseguida y usufructuada por las autoridades:

Venezuela se volvió una corrupción tan atroz... el gobierno por querer mantener una fachada empuja a la gente a ser... a no llevar las cosas claras. Por lo menos las facturas que le daban a mi papá decían un monto por si acaso la policía te paraba y te revisaba la mercancía - pues tú tenías que mostrar la factura, y tenía un monto - pero en realidad jmi papá la pagaba al triple! [...] Así era todo, incluso nosotros vendíamos huevos, mi papá iba a las granjas y vendíamos cubetas de huevos, y eso era como contrabandear marihuana... no sé, mira, yo quedaba tan sorprendida ${ }^{66}$.

Todo en su conjunto revela un estado de excepción marcado por la recursividad, donde las circunstancias obligan a buscar mecanismos de satisfacción a las necesidades humanas fundamentales. El desplazamiento transfronterizo será un recurso, quizás de los más extremos, que refleja la agudización del panorama teniendo en cuenta que la migración Sur-Sur es un indicador de la exacerbación de la crisis y su consecuente urgencia de la huida. A un extremo nivel de dramatismo deben llegar las condiciones de una nación para que ingentes grupos de habitantes se desplacen a otra que también está rebosante de necesidades. Sin embargo, en estados radicales de conflicto, el destino transicional cumple una función paliativa. Por ello, desde una acepción general, Colombia es percibido como tránsito pues se entiende que un país emergente e insuficiente en la satis- 
facción de derechos, aun con sus propios ciudadanos, no podría ser una opción definitiva:

Colombia no es un paraíso económico. A veces la gente piensa que venirse a Colombia es que tú vas a hacer fortuna, que vas a hacer yo no sé qué iy no! Es mentira. Porque uno viene acá es a tener una calidad de vida... calidad de vida en el sentido de que tienes tus servicios, de que puedes salir y no te van a matar, calidad de vida de que tú puedes ir a comerte lo que quieras, calidad de vida de que tú puedes ir a la tienda y comprarte lo que quieras, esa es la calidad de vida y la paz que consigue el venezolano acá en Colombia, mas no que tú te vas a desarrollar económicamente, vas a hacer una fortuna acá y luego te vas a ir a Venezuela, porque es mentira; a menos que seas muy afortunado y que en varios años puedas lograr eso ${ }^{67}$.

Se trata, pues, de un retorno a una condición de regularidad social basada en libertades democráticas fundamentales, pero que por sí mismas no aseguran un poder adquisitivo en el corto plazo, ni un proyecto de sostenibilidad a futuro, ni proveen los beneficios derivados de una mínima estabilidad laboral. La docente valora esta situación desde algunos sentidos característicos. En primer lugar, la percepción de Colombia como alternativa transicional hacia otras naciones latinoamericanas como Ecuador, Perú y Chile donde, se presume, existen condiciones de mayor estabilidad laboral y de aceptación social. De esos países llama la atención el esquema de sus políticas migratorias, las economías dolarizadas y las medidas de protección social que, eventualmente, pueden favorecer a los venezolanos expatriados y a sus ideales de proyectos futuros:

Chile, Perú... son sitios donde los venezolanos van, ¿por qué? Porque por ejemplo Perú tiene políticas migratorias más flexibles que las de Colombia. Y la gente es más receptiva, por ejemplo, las personas que han llegado allá consiguen trabajo en dos, tres días. Hay fuente de trabajo. Aquí es todo un tema conseguir un trabajo [...]. Perú tiene cultura migratoria, aunque hay xenofobia, pero no en esa magnitud como la puede haber aqui en Colombia, como la puede haber en otro país. En Chile también, como está un poco más desarrollado tienen otra perspectiva, ellos acogen a los venezolanos, claro desde su política migratoria, cada país es autónomo en eso, pero ellos tienen otro tipo de políticas. Entonces los venezolanos se van para allá porque vale más el peso chileno, no sé si es verdad, y todo ese tipo de cosas. Entonces uno ya empieza a estudiar los países, ya el venezolano se vuelve astuto en eso, en buscar las opciones ${ }^{68}$.

Sin embargo, resulta llamativo que, como parte del contexto latinoamericano, esas naciones también poseen connotaciones de emergencia que parecen diluidas en el imaginario construido alrededor de ellas como países de restauración para los migrantes. Quizás porque la expectativa de progreso económico se concibe integrada a un sistema social donde, además de las opciones laborales 
y de aseguramiento de captación de ingresos, se provea un ambiente propicio para la integración y el respeto de la diferencia cultural. De aquí se deriva un sentido de singular interés en las concepciones de la maestra migrante, a saber, la responsabilidad humanitaria en el país de destino basada en construcciones de alteridad y de memoria.

Por lo anterior, la xenofobia colombiana, aunque pueda ser comprendida desde razones históricas por la tendencia a la homogenización nacionalista de su proyecto republicano, es ante todo una manifestación paradojal para un país cuya identidad no se comprende al margen de un largo conflicto armado, donde la guerra y las extremas condiciones de inequidad y pauperización han forzado a millones de habitantes al desplazamiento interno y trasnacional. Frente a ello, como ya se ha indicado, Venezuela promovió por décadas un trato incluyente y favorecedor, brindando apoyo a colombianos atraídos durante los años de la bonanza económica. En la voz de la maestra este sentir es claro:

A veces los otros países nos critican a nosotros porque estamos saliendo de nuestro país, no se entiende... más ustedes los colombianos que han tenido que vivir situaciones duras también porque, por lo menos el conflicto armado y todo eso, que los sacan de sus casas... yo pensé de una u otra manera que eran mentiras pero cuando uno vive acá - claro, no lo he visto-pero sí he conocido gente que ha vivido eso, testimonios de eso, entonces uno pudo haber criticado en aquel momento los colombianos que se iban a Venezuela, pero en ese momento la gente no andaba pendiente de eso ${ }^{69}$.

Un aspecto específico que refleja las construcciones de alteridad y de memoria deseables en torno al fenómeno de los desplazamientos transfronterizos, se sitúa en las condiciones de dignificación del trabajo. Además de que la coacción de las circunstancias lleva a los profesionales migrantes a realizar oficios que no son propios de su formación - fenómeno que identificamos como movilidad social regresiva - la maestra identifica un sentimiento adverso que está relacionado directamente con el ambiente creado para el desempeño de los oficios y una totalización de la vida laboral:

A veces los dueños, aquí particularmente en Colombia, son muy prepotentes y creen que siempre van a tener el poder en las manos, pero hay momentos en que no es así; y a veces decían cosas que lo herían a uno, en el sentido de que eran humilladores [...]. Entonces dejas de vivir para sobrevivir. Y esa es una realidad del colombiano, día a día, yo lo veo, y es algo como que... así tampoco se vive, así tampoco es la vida porque uno como ciudadano tiene que tener calidad de vida $y$ calidad de vida es tiempo con tu familia, tiempo para ti mismo, y que no se vuelva una absorción de gente, o sea, de que el único que tiene vida es el dueño de la empresa, más nadie ${ }^{70}$. 
En un marco de responsabilidad humanitaria, como es debido a la urgencia global de la migración, antes de obligaciones legales prevalecen las deudas éticas frente a las cuales se destaca el carácter humano del fenómeno social, el trato solidario y la oportunidad justa sin ingenuidades románticas o vacilaciones pragmáticas. Por eso es necesario convertir la política en programas efectivos y en compromisos ciudadanos precisando los alcances de los pactos multilaterales, el compromiso del Estado receptor y la acción conjunta de las asociaciones civiles. Todo dirigido hacia cierta versión inédita de una ética del cuidado que reciba en forma digna a los caminantes y otorgue protección al vulnerable como saber pedagógico integrado a la formación continua de los docentes.

\section{CONCLUSIÓN}

En el presente estudio se han hecho manifiestas una serie de identidades proyectivas y transicionales que se explican por los cambios vividos por la maestra en su paso por distintos sistemas educativos, sociales y personales, tránsitos que se incentivan singularmente por la intensidad de la experiencia migratoria. De tal manera que no se constata una afinidad lineal con la actualidad de los proyectos, desempeños $u$ oficios, sino que se aprecia un estado de dislocación permanente donde renacen las condiciones para una realización personal y profesional.

Pertinente resulta aquí el señalamiento de Freire: "No nací para ser un profesor así. Me fui haciendo de esta manera en el cuerpo de las tramas, en la reflexión sobre la acción, en la observación atenta de otras prácticas o de la práctica de otros sujetos, en la lectura persistente y crítica de textos teóricos, no importa si estaba o no de acuerdo con ellos"71.

En ese horizonte aparece la capacidad de moldear la profesión docente a partir de transacciones biográficas donde la reflexión de lo vivido actualiza la comprensión de sí mismo frente a la educación. Se afirma, pues, la importancia de la realidad subjetiva de los profesores en la práctica educativa, no sólo como instrumentadores o ejecutores de dispositivos sino como hermeneutas del mundo social, escolar e individual. Así, en la constitución de identidades, "los significados que los docentes atribuyen a su trabajo, en términos de creencias, actitudes y emociones, son existenciales, altamente personales, resistentes a la persuasión y de carácter bastante evaluativo"72.

La experiencia vital acumulativa aparece en la narración como una línea de sentido que va convirtiendo los acontecimientos vividos, sin cálculo o preparación, en aprendizajes útiles para el afrontamiento humano ante situaciones imprevistas, como aquellas derivadas de la migración forzada. La educación para asumir la existencia, incluso ante la fatalidad de su destino, se convierte en una expresión privilegiada de la acumulación de recursos biográficos constituidos en la multiplicidad de espacialidades, temporalidades e interrelaciones. La pe-

71 Paulo Freire, Política y Educación (México: Siglo XXI, 1996), 97.

72 Avalos, "La profesión docente", 242. 
dagogía se encuadra, epistémicamente, como sistema de vida y la construcción de saber docente como posicionamiento preteórico ante el sistema-mundo que lo articula.

De esta forma, los dos grandes bloques de sentido que se han expuesto (tablas 1 y 2), estructuran un sistema de comprensiones del saber pedagógico del maestro migrante donde se descubre, en su conjunto, la categoría dominante de aprendizaje experiencial, entendido como el conjunto de acontecimientos socio-históricos que, al afectar la cotidianidad personal de la maestra, crean un universo de sentido fundado en el análisis reflexivo y prospectivo del presente. La intensidad acumulada de vivencias en los modos de desarrollar la profesión docente, particularmente en el último lustro, lleva a la maestra a afirmar: "todo eso hoy en día me ha enriquecido profundamente en mis valores éticos y morales, y en mi manera de ver la sociedad"73.

El aprendizaje experiencial es una forma particular y englobante de conocimiento práctico, esto es, de un conocimiento constituido y activado contextualmente que complementa el ámbito estrictamente científico, técnico o disciplinar, e integra los sistemas normativos vigentes, por lo cual se constituye también como un conocimiento cultural.

Bien lo sintetiza Tardif al señalar que los fundamentos de la enseñanza son, al mismo tiempo, existenciales, sociales y proyectivos: “Un maestro 'no piensa sólo con la cabeza', sino 'con la vida', con lo que ha sido, con lo que ha vivido, con lo que ha acumulado en términos de experiencia vital, en términos de bagaje de certezas. En suma, piensa a partir de su historia vital, no sólo intelectual, en el sentido riguroso del término, sino también emocional, afectiva, personal e interpersonal" 74 .

Y el mismo autor continúa advirtiendo que el profesor no puede reducirse a la figura del "sujeto epistémico" que establece una relación epistemológica canónica con el mundo a partir de su sistema cognitivo, sino que es un "sujeto existencial", "una persona completa con su cuerpo, sus emociones, su lenguaje, sus relaciones con los otros y consigo mismo. Es una persona comprometida con y por su propia historia - personal, familiar, escolar, social - que le proporciona un bagaje de certezas, a partir de las cuales comprende e interpreta las nuevas situaciones que lo afectan y construyen, por medio de sus propias acciones, la continuación de su historia" 75 .

En ese bagaje de "certezas" radica el universo de significaciones y creencias sobre el ámbito de la acción docente aunque, paradójicamente, se constituya entre coordenadas de incertidumbre como es propio de los contextos migratorios. De ahí que el desplazamiento transfronterizo de profesores, además de expresar la emergencia progresiva de la diversidad en un marco de alerta humanitaria global, es constituyente de un escenario de saber donde la acción reflexiva se combina con el intercambio cultural basado en valores, sentimientos y formas

73 Entrevista 1 a Narvelis Rondón, Tunja, abril 16 de 2018.

74 Tardif, Los saberes del docente, 75 .

75 Ibíd., 76. 
de vida que se instalan y se difunden progresivamente en las comunidades de salida y de destino ${ }^{76}$. Así se configura una línea articuladora de sentido entre construcción biográfica, saber pedagógico y fenómeno migratorio, como es apreciable en el universo interpretativo de la maestra Narvelis Rondón Araujo.

Dichas articulaciones podrán contribuir, en general, a la formación de los nuevos docentes; y, en el caso particular de la UPTC, donde se inscribe esta investigación, a la revitalización de los idearios pedagógicos y formativos estipulados en los distintos tipos de Prácticas Pedagógicas Investigativas, teniendo en cuenta que la educación "es multidisciplinar y la formación del educador en las facultades de Ciencias de la Educación, sólo se puede establecer desde la construcción de sujetos críticos, con identidad y liderazgo social"77.

\section{FUENTES}

Entrevista 1 realizada por Andrés Argüello Parra, Tunja, abril 16 de 2018. Entrevista 2 realizada por Andrés Argüello Parra, Tunja, abril 18 de 2018. Entrevista 3 realizada por Andrés Argüello Parra, Tunja, abril 24 de 2018. Entrevista 4 realizada por Andrés Argüello Parra, Tunja, mayo 9 de 2018. Taller biográfico realizado en Tunja el 27 de junio de 2018.

\section{REFERENCIAS}

Aróstegui, Julio. La historia vivida. Sobre la historia del presente. Madrid: Alianza, 2004.

Avalos, Beatrice, Paula Cavada, Marcela Pardo, Carmen Sotomayor. "La profesión docente: temas y discusiones en la literatura internacional". Estudios Pedagógicos XXXVI, no. 1 (2010): 235-263.

Bertaux, Daniel. Los relatos de vida. Perspectiva etnosociológica. Barcelona: Bellaterra, 2005.

Dao, Thu Hien, Frédéric Docquier, Maurel Mathilde, Pierre Schaus. "Global Migration in the 20th and 21st Centuries: the Unstoppable Force of Demography". FERDI Working Papers, HAL archives-ouvertes, WP223 (1-36). 2018. Acceso el 10 de julio de 2018. https://hal.archives-ouvertes.fr/hal-01743799/document.

De Tezanos, Araceli. “Oficio de enseñar-saber pedagógico, la relación fundante”. Educación y ciudad. Revista del Instituto para la Investigación Educativa y el Desarrollo Pedagógico, no.12 (2007): 7-26.

Elías, Norbert, John Scotson. Establecidos y marginados. Una investigación sociológica sobre problemas comunitarios. México: Fondo de Cultura Económica, 2015.

Fazio, Hugo. La historia del tiempo presente: historiografía, problemas y métodos. Bogotá: Universidad de los Andes, 2010.

Ferrarotti, Franco. "On the Autonomy of the Biographical Method". En Biography and Society: the Life History Approach in the Social Sciences. Compilado por Daniel Bertaux. London/Beverly Hills: Sage Publications, 1981.

Freire, Paulo. Política y Educación. México: Siglo XXI, 1996.

Herrera, José Darío, Angela Martínez. “El saber pedagógico como saber práctico". Pedagogía y saberes, n. ${ }^{\circ} 49$ (2018): 9-26.

Massey, Douglas S., Joaquín Arango, Hugo Graeme, Ali Kouaouci, Adela Pellegrino, J. Edward Taylor. "Theories of International Migration: A Review and Appraisal". Population and Development Review 19, no. 3 (1993): 431-466.

76 cfr. Massey, "Theories of International Migration”, 453.

77 Diana Elvira Soto Arango; José Pascual Mora García y José Rubens Lima Jardilino, “Formación de docentes y modelo pedagógico en la Universidad Pedagógica y Tecnológica de Colombia”, Revista historia de la educación latinoamericana 19, no. 29 (2017): 55. 
“Migración Colombia. Dinámica migratoria Colombia-Venezuela, primer semestre 2018". Migración - Ministerio de Relaciones Exteriores, 2018. Acceso el 1. ${ }^{\circ}$ de agosto de 2018. http:// www.migracioncolombia.gov.co/index.php/es/prensa/infografias/7923-infografia-general.

Mora, José Pascual. “La comisión de Bioética de la Universidad de Los Andes y la fundamentación epistemológica de la comisión de bioética transfronteriza". Revista Mundo FESC 10 (2014): 31-45.

Leal da Costa, Conceição, Ilane Ferreira. "Alteridades(s), escritas de si e reflexão: olhares cruzados sobre a formação de professores em Portugal e no Brasil". Revista Brasileira de Educação de Jovens e Adultos 5, n. ${ }^{\circ} 10$ (2017): 108-126.

Lechner, Elsa, coord. Rostos, Vozes e Silêncios. Uma pesquisa biográfica colaborativa com imigrantes em Portugal. Coimbra: Almedina/CES, 2015.

Lechner, Elsa, Zeila de Brito. "Migrações, pesquisa biográfica e (auto) biográfica: apresentação", Revista Brasileira de Pesquisa (Auto)Biográfica 3, no. 7 (2018): 14-20.

Lozano, Fernando, Lucía Gandini. “Migración calificada y desarrollo humano en América Latina y el Caribe". Revista Mexicana de Sociología 73, n. ${ }^{\circ} 4$ (2011): 675-713.

Passeggi, Maria da Conceição. "A pesquisa (auto) biográfica: por uma hermenêutica descolonizadora". Coisas do Gênero 2, no. 2 (2016): 302-314.

Passeggi, Maria da Conceição, Elizeu Clementino de Souza. “O Movimento (Auto) Biográfico no Brasil: Esboço de suas Configurações no Campo Educacional”. Investigación Cualitativa 2, no. 1 (2017): 6-26.

Rivas, José Ignacio. “El ser humano como narración histórica: aprendiendo desde la acción”. Diálogos. Educación y formación de personas adultas 3, n.os 75-76 (2013): 24-30.

Sayad, Abdelmalek. La doble ausencia. De las ilusiones del emigrado a los padecimientos del inmigrado. Barcelona: Anthropos, 2010.

Soto Arango, Diana Elvira, José Pascual Mora García, José Rubens Lima Jardilino. "Formación de docentes y modelo pedagógico en la Universidad Pedagógica y Tecnológica de Colombia". Revista historia de la educación latinoamericana 19, no. 29 (2017): 35-66.

Tardif, Maurice. Los saberes del docente y su desarrollo profesional. Madrid: Narcea, 2004.

Zambrano Leal, Armando. "Naturaleza y diferenciación del saber pedagógico y saber didáctico". Pedagogía y saberes, no. 50 (2019): 75-84.

Zuluaga, Olga Lucía. Pedagogía e historia. Bogotá: Siglo del Hombre - Universidad de Antioquia, 1999.

Cómo citar:

Argüello Parra, Jaime Andrés. “Construcción biográfica del saber pedagógico de una maestra migrante venezolana en Boyacá". Revista Historia de la Educación Latinoamericana. Vol. 21 No. 33 (2019): 187-219

https:https://doi.org/10.19053/01227238.9097

(c) (i) @) Es Esta obra está bajo una licencia Creative Commons. Reconocimiento-No Comercial-Sin Obra Derivada 2.5 Colombia. 